\title{
Formação Docente para a Diversidade e a Inclusão
}

\author{
Margareth Diniz \\ dinizmargareth@yahoo.com.br
}

\section{Resumo}

A diversidade presente nas escolas atuais e os constantes questionamentos que se apresentam à educação fazem emergir um novo conhecimento escolar que passa a exigir múltiplas habilidades do(a) professor(a). Que tipo de formação o(a) professor(a) precisa para lidar com tantas situações que envolvem a diversidade e as políticas de inclusão em curso no Brasil? Quais os recursos internos/subjetivos que ele precisa mobilizar em si para ensinar aos alunos? O presente artigo tem como objetivo discutir a formação docente visando às múltiplas situações em que se veem envolvidos durante uma jornada de trabalho, a partir da metodologia da conversação, realizada com grupos de docentes, elucidando em seus resultados o caráter provisório do saber e da formação docente.

Palavras-Chave: formação docente; subjetividade; diversidade; inclusão.

\section{$1 \mathrm{O}$ contexto sócio-histórico cultural educacional}

Uma professora de 52 anos diz na conversação que não suporta mais ser professora, que quer se aposentar, pois essa história agora de colocar crianças que tem paralisia cerebral junto com as outras para ela é insuportável. Ela diz que o aluno tem problemas graves, grita, bate o pé pra fazer o que quer. Diz que gosta muito de dar aula, mas não aguenta mais a presença desse aluno.

1 Professora adjunta de Psicologia da Universidade Federal de Ouro Preto. Integrante do Programa de Pós-Graduação do Mestrado em Educação da UFOP. 
Uma outra relata que o seu sofrimento se refere às crianças pobres e negras que vão à escola apenas para comer..que não querem aprender nada... Uma terceira diz da sua dificuldade com os adolescentes que querem insistentemente falar de sexualidade e trazer à tona as experiências que vivem com meninos e meninas.

Um professor se refere a uma situação em que recebeu por ordem do juiz um adolescente de 12 anos que tinha matado uma criança e estava cumprindo medida socioeducativa. (DINIZ, 2010)

O mundo contemporâneo, desde a segunda metade do século $\mathrm{XX}$, assiste sistematicamente à emergência de movimentos sociais urbanos e não urbanos que lutam pelo reconhecimento de suas ideias e concepções políticas. Diferentes grupos passaram a manifestar suas formas de ver o mundo (gays, lésbicas, mulheres, crianças, jovens, velhos, punks, pessoas com deficiência e $\backslash$ ou necessidades especiais, índios, negros) em contraposição a um modelo hegemônico que valorizava a homogeneização e uma pretensa igualdade no trato social. Esses grupos, então, estão requerendo da sociedade capitalista a igualdade de direitos em relação aos que se enquadram nos modelos pré-estabelecidos. A novidade que esses grupos e os movimentos por eles engendrados apresentam é o conceito de diferença, que passa a ser entendida como o reconhecimento das múltiplas formas de manifestar os gêneros, a sexualidade, a etnia etc. A diferença se alia à constituição das novas identidades que passam a configurar-se na ordem social vigente. Esses sujeitos exigem o direito de manifestar sua subjetividade e identidade cultural marcadamente singular e não fixa, podendo ser provisoriamente atraentes e, depois, descartadas, abandonadas, rejeitadas.

A partir dessas mudanças manifestas no campo social, cultural e educacional, intensificadas na década de 1990, surgiram questões que colocam os profissionais que atuam diretamente com o público que frequenta esses espaços em situações embaraçosas. A partir da pluralidade de manifestações comportamentais, religiosas, políticas, sexuais, estéticas, de pensamento e inúmeras outras, os profissionais da educação têm se perguntado: o que fazer? Como agir em relação 
a essas diferenças? Como lidar com os diferentes sujeitos que manifestam e querem manifestar-se de formas variadas no tecido social e consequentemente na escola?

Atualmente, observamos uma intensificação social da temática da diversidade cultural, que, por sua vez, impacta a sociedade, e especialmente a educação, de forma intensa: de um lado, situações de violência e de discriminação racial, de gênero, de condição social, de sexualidade, de diferenças físicas, mentais e tantas outras que ocupam a cena da cultura escolar e social, muitas vezes traduzidas em exclusão. Do outro, a tentativa de absorvê-la a partir de políticas de direitos universalistas que defendem seu pertencimento, mas evidenciam as particularidades subjetivas que por vezes também escapam a essa perspectiva.

$\mathrm{Na}$ formação docente inicial e continuada, muitos profissionais expõem situações que envolvem as práticas educativas formais e não formais. $\mathrm{O}$ que temos constatado nos discursos dos profissionais da educação é que a formação inicial dos cursos de graduação não tem suprido essa formação. Esses profissionais não se sentem preparados para lidar com essa gama de questões, embora já tragam em seus discursos a vontade de construir uma sociedade inclusiva. Silenciadas nos conteúdos disciplinares e nos aspectos mais gerais da formação desses profissionais que atuam no campo educacional, as questões que envolvem as diferenças ficam, muitas vezes, reservadas às suas vivências e atuações nas quais se veem impotentes diante dessa diversidade de situações. Dessa forma, aprendizagens caricatas sobre as diferenças vão se tecendo no espaço escolar, alargando e fomentando importantes preconceitos construídos pela humanidade. Pensar e desenvolver uma formação que visa a forjar práticas educativas para o público da diversidade implica pensar tanto as teorias e os campos de saber propícios a essa formação, quanto considerar a subjetividade do(a) docente para enfrentar a gama de valores que geram conflitos tão presentes nos espaços educativos e nas políticas públicas educacionais. As práticas dos profissionais que atuam com esse público estão marcadas por uma formação precária para atuar com esses sujeitos, pois em grande parte sua formação baseou-se num modelo em que a questão ética não se fez presente, não interrogando os 
valores subjetivos dos professores e professoras, escondendo também os sujeitos submetidos a essas práticas. O modelo da racionalidade técnica que vigorou por muito tempo na formação docente não era e não é capaz de considerar a existência de sujeitos em sua particularidade, nem a dos(as) formadores(as) nem dos(as) alunos(as) que hoje frequentam as escolas.

A seguir farei uma breve retomada desse modelo na formação docente para, em seguida, avançar um pouco nesse paradigma, discutindo quais seriam os princípios a serem considerados em uma formação docente para a diversidade e inclusão numa perspectiva ética.

\section{Breve retrospectiva dos elementos presentes na formação docente}

Os estudos produzidos sobre a formação e o trabalho docente têm apresentado mudanças ao longo das décadas. As linhas de pesquisa, até a década de 1960, centravam suas investigações em encontrar características pessoais do professor e relacioná-las à aprendizagem dos alunos².

No início da década de 1970, as investigações sobre o professor sofrem uma mudança de paradigma ao focalizarem os estudos não mais em características pessoais, mas na situação de ensino propriamente dita, centrando-se na observação e análise da atuação docente. Ao final dessa década, enfatizou-se a investigação sobre o professor cuja preocupação residiu nos processos de pensamento e de tomada de decisões dos docentes durante sua atividade profissional.

A discussão sobre a formação vem se destacando muito nas conferências e seminários sobre educação desde o final da década de 1970, época em que se iniciou um movimento de reflexão sobre a escola brasileira, partindo de sua realidade, buscando caminhos que permitissem a saída da crise em que se encontrava tanto a escola brasileira, quanto o ensino que nela se efetivava. A preocupação com o

2 A despeito da minha opção em incorporar neste texto as recentes discussões sobre gênero, anunciando correntemente, por exemplo, "professor" e "professora", ao invés de tão somente o modo genérico e habitual da língua culta "professor", dada a perspectiva histórica do apanhado das concepções sobre formação e profissão docente nos anos 1960, 1970 e parte dos anos 1980, o debate sobre gênero ainda não havia resultado na mudança no estilo de escrita. Daí, optar nesta parte do texto em manter a forma genérica de tratar o gênero masculino e o feminino. 
fracasso escolar levou os educadores à discussão e à análise dos fatores responsáveis pela baixa qualidade do ensino e da possibilidade de se oferecer uma boa escola à população de baixa renda. Evidenciou-se a necessidade de melhorar a formação dos professores como condição para a melhoria da qualidade do ensino em geral.

Durante os debates ocorridos no "I Seminário de Educação Brasileira", realizado na Universidade Estadual de Campinas, em 1978, foi muito discutida a ideia de que as licenciaturas e o curso de pedagogia deveriam, antes de tudo, formar o educador; ressaltando-se, assim, a primazia do ato de educar sobre o ato de ensinar.

Os enfoques investigativos do início dos anos 1980 referem-se ao caráter político da prática pedagógica e ao compromisso do educador com as classes populares. Nesse momento, procurou-se definir a natureza da função docente e o papel do educador para se direcionar às reformas dos cursos de formação de educadores.

Após os primeiros anos da década de 1980, a preocupação com a formação técnica do educador ganhou considerável importância, ao mesmo tempo que a questão da formação política do futuro educador. Nesse contexto, a competência técnica (traduzida pelo domínio do conteúdo do saber escolar e dos métodos adequados para se transmitir este conteúdo às crianças que não apresentam pré-condições estabelecidas para sua aprendizagem), à qual subjaz um suporte pedagógico e um compromisso educacional e social, apresenta-se como condição necessária para que o educador assuma um compromisso político. A formação técnica deveria envolver tanto o conhecimento específico de determinado campo, quanto o conhecimento pedagógico, o que gerou inúmeras críticas de educadores em relação à estrutura e ao conteúdo dos cursos de formação de professores e especialistas cuja marca era a justaposição da parte de conteúdo específico à de formação pedagógica.

Outra vertente que se fez valer na década de 1980 foram as pesquisas sobre o pensamento do professor, que focalizam o seu conhecimento prático pessoal. Para Nóvoa (1991), nesse paradigma, a concepção de professor é a de um profissional ativo, autônomo, que reflete, analisa e interpreta sua própria prática. $\mathrm{O}$ paradigma norteado pelo pensamento 
do professor deu início a diversas investigações que analisaram os tipos de conhecimentos que os professores elaboram e utilizam no cotidiano escolar. Os estudos dos processos de pensamento e ação do professor ressaltam duas dimensões da cognição: o processamento de informações e a tomada de decisões. Nesses dois enfoques investigativos dos processos de pensamento dos professores, destacam-se que o modelo de tomada de decisões estuda como o professor decide e o que deve fazer frente a uma situação específica. Junto a isso, o modelo de processamento de informação procura relacionar a definição de ensino que o professor possui com a sua conduta. Essas duas dimensões da cognição constituem fases de um mesmo processo pelo qual passa o professor face à complexidade das tarefas em que se envolve e que o torna um profissional ativo.

Como o processamento de informações e a tomada de decisões não ocorrem apenas num contexto mental, mas interligam-se às situações vividas pelos docentes, pressupõe-se que os professores têm diferentes tipos de conhecimentos que configuram as suas concepções epistemológicas. É importante destacar, neste contexto, as contribuições de Shulman (1986), pesquisador preocupado com o papel do conhecimento no ensino, nas investigações dos diferentes tipos e modalidades de conhecimento. Com o objetivo de estudar o que sabem os professores sobre o conteúdo que ensinam, onde e quando adquiriram esses conteúdos e como devem ser utilizados no cotidiano escolar, este autor conduziu suas investigações sobre o professor e a sua formação, apontando novas perspectivas investigativas sobre a questão da competência para ensinar.

Mas o modelo da racionalidade técnica, visando a prever ou prescrever o ato docente de educar, pôs de lado o sujeito. O sujeito constituído com base nos efeitos das relações de poder, no que se referem aos valores e produções discursivas, como gênero, etnia, sexualidade, credo, local etc., enunciado nos discursos, passa a trazer à tona o lugar da subjetividade - sempre em relação ao outro social e cultural, tão silenciada estava no discurso da racionalidade técnica. Aqui falamos de uma concepção de sujeito que não é o ser, nem é o indivíduo que muda historicamente e se compõe como parte indivisível (daí o nome) do grupo social, podendo se fazer autônomo, ideal e senhor de seus atos; aqui falamos do sujeito como efeito discursivo, simples 
e puro resultado de um processo de produção social e cultural, tão móvel e singular como são tais processos. É a emergência desse sujeito dividido no campo educacional, até então subsumido pela técnica, que desarticula e interroga os docentes e seus saberes, levando-os à necessidade de romper com os instrumentos, as técnicas e os planejamentos que vêm estabelecidos antes de atingir ou incluir sujeitos, mesmo sendo para eles destinados, pois sabemos que a racionalidade demonstra construir positividades à custa do abafamento dos posicionamentos subjetivos.

Assim, uma prática docente que inclua os sujeitos e suas diferenças exige também uma formação que alcance a concepção de sujeito de nossos tempos como fruto de uma série de rupturas nos discursos do conhecimento racional e científico, levando-os a considerarem que o seu trabalho é marcado por incongruências, incertezas e descontinuidades que o podem formar tanto ou mais que todo e qualquer esforço de agências destinadas a tal fim. Então, considerar que a experiência pedagógica não reserva aos docentes somente positividades pré-concebidas leva-os a inventar (ou reinventar) a educação a todo instante. Os atos dos docentes produzem saberes tão particulares quanto são esses próprios atos, pois são saberes produzidos por sujeitos induzidos de singularidades, muitas vezes à revelia das prescrições educativas.

Assim, a década de 1990 passa a valorizar os saberes da experiência, a partir das discussões sobre os saberes que um educador e uma educadora precisam ter para se constituírem como profissionais da educação. Surge, então, uma complexidade de teorias e práticas marcadas por rupturas com modelos ou pensamentos sobre trabalho docente e formação de profissionais da educação estabelecidos anteriormente, consentindo com um sujeito também produtor de saberes, sempre induzido pelas relações de poder fabricadas no ato de educar.

\section{A perspectiva teórica, prática e subjetiva condizente com uma formação para a diversidade}

Geralmente, as teorias que discutem a formação docente centram-se no debate sobre método e o procedimento didático, ou seja, em sua dimensão técnica, atribuindo a esses um melhor ou pior resultado da formação. 
É o que visamos a superar, considerando que a escolha da teoria, a consideração dos saberes práticos e a subjetividade se aliam na formação docente que visa a incluir a diversidade humana.

Hall (2002) condensa em cinco itens os avanços das ciências humanas e sociais sobre o descentramento do sujeito cartesiano. $\mathrm{O}$ primeiro descentramento ele atribui ao pensamento marxista que sujeita o homem e a mulher às condições sócio-históricas que os constituem, tornando-os alienados, pois agem apenas mediante condições materiais, históricas e econômicas criadas por outros.

O segundo descentramento vem da descoberta freudiana do inconsciente que divide o sujeito entre o sentido e a pulsão, definindo-o por um inevitável embate com o outro que o habita. Aqui, como em Marx, o sujeito não é mais o dono de sua própria história, capaz de transformar o mundo a partir da tomada de consciência, como se, percebendo a dominação e a força do outro, o sujeito pudesse lutar e chegar à condição paradisíaca e originária de sujeito uno, pleno de poder.

O terceiro descentramento é causado pela linguística estrutural de Saussure, que diz ser o significado inerente e instável, sempre escapando ao indivíduo. Não somos, de modo algum, autores das afirmações que fazemos ou dos significados que expressamos na língua. Através de significantes, buscamos alcançar significados plenos e fechados, fixando uma identidade, mas tais significados são constantemente perturbados pela diferença, sempre por desestabilizar certezas discursivas.

O quarto descentramento trata-se de uma genealogia do sujeito moderno ou uma arqueologia do biopoder propostas por Foucault. Tal genealogia é constituída pelo poder disciplinar que, antes do indivíduo e do corpo, preocupa-se com a regulamentação e com a vigilância de homens, mulheres e populações inteiras. Para isso, as instituições como escolas, prisões, hospitais, clínicas, quartéis e tantas outras que compõem a modernidade, são amplamente requeridas, construídas e utilizadas no sentido de policiarem e disciplinarem as vidas, o trabalho, os saberes, a saúde física e mental, as práticas sexuais, os hábitos familiares, as infelicidades e os prazeres dos mais diversos sujeitos submetidos a essas instituições.

Por fim, o quinto descentramento, para o autor, advém dos 
movimentos sociais: o feminismo, a contracultura, as manifestações pró-ecológicas, as lutas pelos direitos civis, étnicos, sexuais, de gênero etc., que politizaram a subjetividade. Juntam-se a isso, os movimentos antibelicistas das décadas de 1960 e 1970, as revoltas estudantis (tendo as de maio de 1968 como as mais proeminentes), as lutas antiditatoriais do terceiro mundo, bem como as manifestações que se opunham tanto à política liberal capitalista do ocidente, quanto à política estalinista do leste europeu e partes das Ásia.

Dessa forma, instituíram-se nas ciências humanas dimensões subjetivas à política, ao lado de dimensões tão somente objetivas, pois cada movimento reivindicava uma identidade própria. Nascia, então, uma política de identidade que, para além de simples manifestações de posição social e de contestação, fez desestabilizar uma identidade fixa e centrada (como, por exemplo, a branca, masculina, burguesa, heterossexual e cristã) em favor de novas formas de subjetividade que admitem em si mesmas também o lugar da contradição, do inacabamento, da incongruência e da descontinuidade.

Tudo isso faz ressonância no campo educacional. Esse processo de construção de identidade é um processo complexo através do qual cada educador e educadora em formação, bem como as demais personagens da esfera educativa, narram suas subjetividades de maneira diversa, agora influenciados pelos discursos ideológicos e políticos dos movimentos sociais, marcados, por sua vez, pelas lutas de poder, bem como divididos por pulsões inconscientes e pelas condições históricas que as constituíram. $\mathrm{O}$ que somos como educadores e educadoras e o trabalho pedagógico que realizamos vêm do desejo, de experiências, do lugar social, da luta de poder, de significantes que instauram discursos, de acasos que se consolidam em gestos, rotinas, ações, comportamentos que nos fazem nos identificarmos como docentes.

Assim, pensar uma formação docente que considere a diversidade humana implica considerarmos os valores, as normas, os discursos, os princípios que os sujeitos interiorizaram ao longo de suas trajetórias de vida e, ainda, a forma como os exteriorizam, transformando-os em atos diante da realidade objetiva. Há de se considerar também, ao lado de 
valores e princípios enunciados, os traços inconscientes e as insurreições pulsionais que constituem o trabalho docente tanto quanto as prescrições formadoras. A aposta é que possamos ter acesso a esses aspectos do trabalho docente, visando a entender as escolhas e atitudes que caracterizam as possíveis subjetividades de cada educador e educadora, suas definições com relação à concepção de aluno, de educação, de escola e do seu próprio papel social, escutando como cada um se posiciona sobre as concepções pedagógicas e sobre seu posicionamento político e subjetivo frente ao ato de ensinar.

A posição do sujeito no trabalho docente antecede toda e qualquer formação e preparação para o exercício da carreira profissional, associando-se à própria história de vida do educador e da educadora. Sua trajetória individual o induz a um percurso formador e, sem dúvida, não apenas marca, como, sobretudo, determina sua vida profissional. A configuração na formação dos profissionais da educação pelas agências formadoras precisa, então, considerar a tripla dimensão formativa do docente: a teoria, os saberes da experiência e a subjetividade.

Na esteira dos anos 2000, a formação docente proposta por pesquisadores e pesquisadoras que seguem nesse campo de rupturas pretende interrogar os saberes teóricos que os(as) docentes precisam ter numa perspectiva curricular que intencionalmente aponte para a diversidade formativa. Os estudos culturais invocam, assim, as questões sobre identidades e subjetividades, constituindo-se e constituindo sujeitos nos diversos espaços institucionais de caráter educativo e no trabalho docente. Passa-se a considerar como o educador e a educadora são influenciados profundamente pelas identidades étnicas, sexuais, etárias, religiosas e de gênero ao construírem saberes sobre suas práticas.

Aqui se faz necessário introduzir mais alguns elementos que, somados aos estudos culturais, possam de fato alterar significativamente a formação dos docentes.

A partir das discussões que a Psicanálise apresenta acerca do método clínico, da noção de implicação e da noção de relação com o saber, passamos a interrogar o paradigma conceitual professor reflexivo, pois esse paradigma não alcança o inconsciente presente na relação 
professor(a)-aluno(a).

Considerando o paradigma indiciário, buscamos um método capaz de considerar a incompletude do saber no campo científico e, posteriormente, na formação docente. A pesquisa acadêmica que se dispõe a utilizar o método clínico, de acordo com Levy (2001), não despreza a análise da relação entre o(a) pesquisador(a) e seu objeto, entendendo que o seu desafio é o trabalho que consente com a não neutralidade do(a) pesquisador(a) na produção do conhecimento. Os percalços na construção de um conhecimento fazem parte do processo, por isso não devem ser escamoteados.

Importante destacar que um dos fundamentos do método clínico é a noção de sujeito, já elucidada neste texto, ao considerá-lo como sujeito do inconsciente, sujeito da falta. Inventar uma experiência de ensino congruente com o consentimento do inconsciente colocaria o sujeito não só em relação com o saber diferente daquele que se produz no ensino acadêmico, uma vez que esse não considera as emergências do inconsciente, mas também, e por isso mesmo, em relação aos efeitos de verdade. Saber que temos diferentes relações com o saber em diferentes situações faz diferença para constituir nosso estilo de ensinar. $\mathrm{O}(\mathrm{A})$ educador(a) desavisado(a) de que o saber em sua dupla dimensão forma uma unidade ambígua e contraditória dá à função de ensinar um caráter problemático, uma vez que as questões daí decorrentes são comumente tratadas no registro patológico, principalmente quando se analisa a relação do(a) aluno(a) com a aprendizagem.

Outro elemento é a relação desse sujeito com o saber que se define pela relação que ele estabelece consigo mesmo, com o outro e com o mundo. Esse saber não se reduz ao conhecer propriamente dito (efeito da inteligência), mas também ao orientar-se e ao comportar-se diante da vida, ou diante do saber. É uma posição que move o sujeito ainda que ele não saiba nomeá-la. Nesse sentido, o saber é efeito do desejo inconsciente, de acordo com Santos (1991). A formação inicial exigirá tanto dos profissionais que nela se encontram transmitindo a formação quanto dos(das) professores(as) iniciantes a problematização da relação com o saber em sua dupla dimensão: o conhecimento formalizado e 
organizado em forma de teorias, e um saber não sabido que perpassa as relações educativas, mas que não é aprendido nesse tipo de formação.

É sobre esse saber não sabido, presente nos atos e escolhas dos professores e professoras e também dos alunos e alunas, que pensamos ser importante nos debruçarmos no decorrer dos processos formativos, pois temos nos deparado com situações enigmáticas no que tange tanto à aquisição de conhecimentos formalizados na formação docente, quanto na aquisição da leitura e da escrita por parte dos(as) alunos(as). De um lado, certa impermeabilidade por parte dos(as) professores(as) em assimilar as mudanças propostas no campo educacional e, de outro, os(as) alunos(as) que têm demonstrado certa recusa em relação à educação escolarizada e suas implicações.

Outra questão que o método clínico coloca é a noção de implicação: ao trazer à discussão o método clínico, é inevitável pensar que, ao formular uma pergunta, somos parte da pergunta formulada, colocando-nos em um cenário de incertezas, nem sempre confortável e desejável. Além disso, o método clínico traz à tona a desmistificação do ideal do método, pois reconhece que o produto do trabalho contém em si uma parte de desconhecimento, chamando-o como as zonas cegas, que são elementos nem sempre nomeáveis, de ordem inconsciente. Esse método passa a enfatizar mais os processos que precedem e subjazem os possíveis resultados ou produtos.

O trabalho para que o(a) professor(a) se coloque numa posição investigativa, e não numa posição cujo saber antecede a sua relação com o sujeito aluno(a), é lento. Aprender com o que surge e não submeter a uma rápida explicação os fracassos do ato educativo é consentir com o imponderável, com o desconhecido. É preciso aceitar trabalhar com as "zonas cegas", no dizer de Levy (2001). O(A) professor(a) passa a lidar com a incerteza dos resultados da tarefa de ensinar, com o imponderável, pelo fato de se estabelecer uma relação sujeito-sujeito. Dessa forma, procedimentos como memorial, estudos de caso, relatos de experiência, discussões sobre filmes têm sido utilizados com esse objetivo.

Ao trabalhar com o método clínico é possível narrar e analisar a minha própria relação com o saber e evidenciar a compreensão de um estilo de 
ser, que pode apontar pistas para o estilo de ser professor(a), alterando significativamente a perspectiva da formação docente, pois se passa a abordar a implicação do sujeito professor(a) no processo de ensino. Os impulsos inconscientes, os desejos insatisfeitos, amor e ódio permeiam as relações entre os sujeitos em situação de ensino e de aprendizagem e não são escamoteados quando se opera com esse método. É importante assinalar que o(a) aluno(a) aprende o(a) professor(a).

Dessa forma, o trabalho na formação docente visa a que ele(a) possa elucidar algo do que se apropriou, aquilo que lhe tenha sido significativo, do que se transmite, mesmo sem o saber, nomeada aqui como uma produção do(a) aluno(a), a qual é considerada no procedimento avaliativo, sem julgamento algum a priori. O trabalho em torno da produção se constitui em um procedimento processual, começando pelo convite para conversar sobre temas desconcertantes presentes em suas práticas pedagógicas, principalmente aqueles ligados à diversidade, como podemos constatar na epígrafe deste texto. Sexualidade, gênero, raça e etnia, diferenças em relação à condição física e mental e à situação econômica, indisciplina, toxicomania são alguns desses temas. Conversar é um princípio que orienta o trabalho. Para Miller (2003, p. 36), uma conversação é:

um tipo de associação livre, em que se tem êxito. A associação livre pode ser coletivizada na medida em que não somos donos dos significantes. Um significante chama a outros significantes, não sendo tão importante quem o produz em um momento dado. Se confiamos na cadeia de significantes, vários participam do mesmo. Ao menos é a ficção da conversação produzir - não uma enunciação coletiva - senão uma associação livre coletivizada, da qual esperamos um certo efeito de saber. Quando as coisas passam bem, os significantes de outros me dão idéias, me ajudam e, finalmente, resulta - às vezes - em algo novo, um ângulo novo, perspectivas inéditas.

Assim, aposto que, ao conversar em sala de aula sobre um determinado assunto, possa-se produzir um efeito interrogativo nos sujeitos sobre os elementos subjetivos que perpassam o processo de ensino e de aprendizagem. Buscar a formalização teórica desses elementos é 
consentir que nem todos serão passíveis de elucidação. Por isso, o importante é conversar, trocar significantes.

Nas conversações, os(as) alunos(as), em situação de formação, estão a todo momento a se perguntar se agiram corretamente em uma determinada situação, principalmente quando essa ação envolve o trato com as diferenças subjetivas. $\mathrm{O}$ posicionamento ético permitirá que se faça uma escolha por um determinado procedimento ou ato em sala de aula, e possibilitará ao sujeito assumir essa escolha, pois sempre haverá múltiplas possibilidades de atuação.

A conversa sobre essas possibilidades também funciona como balizador para que cada um(a) decida sobre a justeza de seu ato. A indicação, leitura e discussão sobre textos teóricos só são apresentados após essa conversa. Além disso, a perspectiva de uma possível epistemologia da prática passa a conviver lado a lado com uma episteme universal e hegemônica, que prescreve conhecimentos e modelos de formação. Para isso, uma arqueologia do trabalho docente é requerida nessa perspectiva a fim de investigar como saberes da experiência são construídos com os conhecimentos hegemônicos, sem que os primeiros sejam subsumidos a tais conhecimentos.

A apropriação de elementos teóricos poderão ser captados e enunciados pelos sujeitos; em parte, pois consideramos que os aspectos objetivos dessa formação, os quais nomeamos conhecimento, podem ser explicitados, quanto aos efeitos subjetivos, ligados à singularidade de cada um, ao estilo de cada um, talvez possamos perceber alguns traços que eles e elas poderão elucidar, ou não, pois se torna difícil narrar esse processo no momento de seu acontecimento. Somente a posteriori é possível aos sujeitos dizer se a formação produziu neles algum efeito. Só nos é possível enunciar algo sobre nosso próprio estilo de ensinar.

Objetivamente visamos que a inclusão provoque alterações no que está em geral disponível na sociedade e na escola no que tange aos aparatos e políticas públicas. Essas alterações deverão se dar através da reforma e nova organização do currículo, da avaliação, da pedagogia, das formas de agrupamento de alunos(as), das escolas e do sistema educacional como um todo para responder a uma ampla gama de necessidades, celebrando 
a diversidade de gênero, de raça e etnia, de linguagem de origem, de nível de aquisição de aprendizagem ou a deficiência e suas especificidades. Para isso, teremos que alterar a lógica do aluno como objeto para aluno como sujeito que porta diferenças. Não é possível ensinar tudo a todos ao mesmo tempo. Será preciso rever processos avaliativos, sem que isso signifique ausência de avaliação. O ponto de partida deve ser o que aquele sujeito sabe, o que aprendeu para propor novos desafios e não a comparação com a aprendizagem do outro. Também a função da escola não poderá se restringir a ensinar a ler e a escrever, nem tampouco transmitir conteúdos pré-existentes. Teremos que ampliar essas intenções.

Do ponto de vista subjetivo há ainda mais complexidades a serem enfrentadas, pois trabalhar com as noções de sujeito do inconsciente, de relação com o saber e de implicação é pouco usual e distante das pesquisas acadêmicas e em processos de formação docente, principalmente em nosso país. Trabalhar com uma noção pressupõe que, ao desenvolver práticas que a utilizam e ao descrever os fenômenos balizados por ela, avaliem-se, também, as possibilidades e limites dessa noção, analisando a viabilidade de operar com ela para elucidar problemas e apontar novas leituras da realidade. O método clínico permite essa reflexão, uma vez que não escamoteia os obstáculos e os impasses daí decorrentes.

Nessa perspectiva, a implicação da subjetividade do(a) pesquisador(a) e do(a) professor(a), em seu processo de formação, em suas dimensões consciente e inconsciente, é tratada não como obstáculo à compreensão, mas como um fenômeno a ser reconhecido e trabalhado no processo de produção de conhecimento. Considero também a riqueza de se trabalhar com uma noção, pois a sua fluidez permite que se possa criar e transformá-la, indo além do conhecimento formalizado, estabilizado, permitindo transitar nas fronteiras do desconhecimento, das incertezas, do imprevisível.

O princípio axial neste trabalho é o da incompletude do saber. Partindo do princípio de que há um mal-estar inerente à condição humana e de que não é possível escamotear esse mal-estar, seja na produção de conhecimentos, seja na transmissão desses, a partir da concepção de sujeito dividido e plural, faz-se necessário continuar perguntando: $\mathrm{O}$ que é formar para a diversidade e a inclusão? 


\section{Referências}

DINIZ, Margareth. Relatório de pesquisa: O mal-estar docente e os problemas das crianças e adolescentes. Conversação. UFOP. 2010.

HALL, S. A identidade cultural na pós-modernidade. Rio de Janeiro, DP\&A, 2002.

LEVY, A. Ciências clínicas e organizações sociais. Belo Horizonte, Autência-FUMEC, 2001.

MILLER, J. A. Conversação. IN: MILLER, J. A pareja e o amor. Paidós. Buenos Aires. 2003:36.

NÓVOA, A. O passado e o presente dos professores. In: NÓVOA, Antônio (Org.) Profissão professor. Portugal: Porto, 1991.

SANTOS, E. H. Le savoir em travail: l'expérience de développement technologique par les travailleurs d'une industrie brésiliene. SaintDenis: Université de Paris VIII, Départament des Sciencies de l'Education, 1991.

SHULMAN, L. S. Those who understand: knowledge growth in teaching. Educational Esearcher. v. 15, n. 2. p. 4-14, 1986. 


\title{
Teacher Education for Diversity and Inclusion
}

\begin{abstract}
The diversity present in schools today and the constant questions that present themselves to bring out a new education school knowledge that now requires multiple skills (a) teacher (a). What kind of training the (a) teacher (a) need to deal with many situations involving diversity and inclusion policies in place in Brazil? What internal resources / subjective that it needs to mobilize itself to teach students? This article aims to discuss teacher training aimed at multiple situations that are seen involved during a workday, using the methodology of conversation held with groups of teachers, explaining their results in the provisional nature of knowledge and training teacher.
\end{abstract}

Keywords: teacher education; subjectivity, diversity, inclusion.

Recebido: 20/05/11

Aprovado: 04/08/11 